\title{
Atividade lúdica para o ensino de ciências como prática inclusiva para surdos
}

\author{
Daniel Santos Espindola* \\ Danubia Carneiro** \\ Talicia do Carmo Galan Kuhn*** \\ Lia Maris Orth Ritter Antiqueira****
}

\section{Resumo}

A inclusão de estudantes surdos tem sido cada vez mais observada na realidade escolar, sendo que é essencial que os professores busquem metodologias efetivas nos processos de ensino e aprendizagem. O presente trabalho tem como objetivo geral avaliar o uso da ludicidade como ferramenta de auxilio no ensino de Biomas Brasileiros, contribuindo para uma aprendizagem significativa, promovendo a inclusão de um surdo em uma classe mista. Nessa perspectiva, foi elaborado uma atividade lúdica bilíngue sobre Biomas do Brasil. A pesquisa foi aplicada em uma classe do $6^{\circ}$ ano do ensino fundamental de uma escola da rede estadual de ensino no município de Ponta Grossa, Paraná. A atividade apresentou bons resultados, pois houve o envolvimento de todos os estudantes e abordou-se o conteúdo de forma igualitária. Concluiu-se que há práticas pedagógicas que são capazes de promover a inclusão, desde que, se atente às dificuldades dos estudantes com necessidades especiais. Portanto a atividade lúdica é um instrumento que corrobora para o processo ensino/aprendizagem e promove a interação dos estudantes.

Palavras-chave: Educação inclusiva; Atividade lúdica para surdos; Educação de surdos.

\footnotetext{
* Graduando da Universidade Tecnológica Federal do Paraná, Ponta Grossa, Paraná, Brasil.

** Graduanda da Universidade Tecnológica Federal do Paraná, Ponta Grossa, Paraná, Brasil.

*** Mestre em Ensino de Ciência e Tecnologia pela Universidade Tecnológica Federal do Paraná, Ponta Grossa, Paraná, Brasil.

**** Professora doutora da Universidade Tecnológica Federal do Paraná, Ponta Grossa, Paraná, Brasil.
} 


\section{Playful activity for science education with inclusive practice for the deaf}

\section{Abstract}

The presence of deaf students has been increasingly observed in schools, and it is essential that teachers seek effective methodologies in the teaching and learning processes. The purpose of this work is to evaluate playfulness as an assistance tool in the teaching of Brazilian Biomes, thus contributing to a meaningful learning and promoting the inclusion of a deaf in a mixed class. Therefore, a bilingual leisure activity was elaborated on Biomes of Brazil. The research was applied to a 6th grade elementary school class of the public school system in the city of Ponta Grossa, Paraná, Brazil. The activity showed good results since all students were involved and the content was addressed in an egalitarian way. In conclusion, there are pedagogical practices that are indeed capable of promoting inclusion, provided that the particularities of students with special needs are taken into account. Therefore, playful activities are an instrument that corroborates the teaching/learning process and promotes student interaction.

Keywords: Inclusive education; Playful activity for the deaf; Education of the deaf.

\section{Introdução}

A educação de surdos no Brasil é realizada em salas de aula do ensino regular, visto que há falta de escolas especializadas. Esta também é uma tentativa de se promover a inclusão social destes alunos. Porém, é muito comum que os estudantes com necessidades especiais sejam "deixados de lado" em muitas situaçóes, como por exemplo trabalhos realizados em grupo e momentos de interação com a classe e com o professor. Isso se deve à dificuldade de comunicaçáo entre surdos e ouvintes (quando os ouvintes náo dominam a Língua Brasileira de Sinais -LIBRAS).

Essas condiçôes acabam por refletir no aproveitamento dos conteúdos pelo estudante surdo, que acaba realizando as atividades isolado da turma ou por vezes tem sua capacidade de aprendizagem subestimada, devido às limitaçôes para aquisição de conceitos, considerando que a língua portuguesa é sua segunda língua. Portanto, o estudante surdo muitas vezes fica restrito somente ao contato com o intérprete, criando certa dependência com este profissional.

Estas dificuldades enfrentadas pelos estudantes surdos se devem ao fato de não haver a valorização da cultura surda, o material didático utilizado não ser bilíngue e haver limitação de conhecimento da língua de sinais por parte do professor e dos colegas de turma. Sabe-se também que o ambiente em que o estudante se insere pode contribuir ou náo para o seu crescimento. Estes aspectos convergem para a desmotivação do aluno surdo, provocando a evasáo escolar no ensino regular.

Para superar esta situação é necessário que se busquem práticas pedagógicas que explorem o cognitivo dos estudantes com necessidades educacionais especiais. 
Portanto, utilizar-se de atividades lúdicas e material didático atrelado ao visual facilita a inserção do estudante surdo no contexto escolar e convívio social.

Este trabalho teve como objetivo avaliar o uso da ludicidade como ferramenta de auxilio no conteúdo de Biomas Brasileiros, por meio da elaboraçáo e utilização de um jogo didático, contribuindo para a aprendizagem significativa de modo a promover a inclusão do estudante surdo em uma classe mista ${ }^{1}$. Desta forma também visou-se diagnosticar se o uso da ludicidade contribui para o entendimento do conteúdo proposto e para comunicação/interação entre surdos e ouvintes.

\section{Aprendizagem surda e aprendizagem significativa com uso de atividades lúdicas}

A difusão da língua de sinais tem avançado potencialmente nas últimas décadas no Brasil. Este fato pode ser comprovado pelo aumento do ingresso de surdos no meio acadêmico, nos mais diversos cursos de graduação e pós-graduação, lato e stricto sensu. Este cenário foi favorecido pelo Decreto no 5.626 de 22 de dezembro de 2005 e também pela Política Nacional de Educação Especial na Perspectiva da Educação Inclusiva - PNEEPEI (Brasil, 2008), que difundem a inclusão de surdos na educação em todos os níveis, do infantil ao superior e o reconhecimento da língua brasileira de sinais como língua nacional, bem como formação de professores para o atendimento especializado e outros profissionais para uma educaçấo inclusiva, além da participaçáo da família e comunidade no processo de ensino/aprendizagem, dentre outros fatores como acessibilidade em estrutura predial da escola e transporte destes alunos.

LIBRAS é uma língua expressa através de sinais realizados com as mãos e que podem ser auxiliados por movimentos ou não além de expressôes faciais utilizadas para se relacionar/comunicar entre surdos e/ou surdos com ouvintes. Rodrigues e Quadros (2015) definem linguagem como expressão do pensamento, como instrumento de comunicação, como fundamento da cognição ou como construção da interação.

Nesta perspectiva, o uso de LIBRAS favorece a socialização, o acesso à cultura e criação da identidade do surdo, pois é somente com a influência do meio que se constrói a identidade do indivíduo, através das relaçôes pessoais. Rodrigues e Quadros (2015) relatam que os ganhos surdos no campo da linguagem são: as experiências relatadas (principalmente na comunidade acadêmica), a difusão de libras (quando o ouvinte se espelha no surdo e aprende a modalidade gesto-visual), além da influência das expressóes faciais na comunicação.

Atualmente, a política educacional inclusiva, tem amparo legal e princípios teóricos democráticos de igualdade, equidade e diversidade. Mas, para a comunidade surda, a realidade das práticas educacionais inclusivas, está distante das proposiçóes teóricas e legais (Rossi, 2012).

Machado (2006) afirma que a especificidade linguística do surdo faz a sua inserção nos meios comuns de ensino uma situação muito complexa e diferente da- 
quela que poderá ser vivenciada pelos alunos cegos, deficientes mentais, deficientes físicos, etc. Muitos dos estudantes surdos acabam desistindo porque não conseguem acompanhar instrução em português falado, já que o método mais utilizado é fundamentado no oralismo.

Apesar das políticas públicas que amparam a proposta de inclusão, as escolas na maioria das vezes precisam buscar meios próprios de acolher a todos os alunos, segundo a sua própria realidade, o seu contexto e o seu compromisso com toda a comunidade. Na visão de Rossi (2012) o ideal seria implantar uma estrutura educacional com preparação e adaptação de acordo com a situação para que as instituiçôes de ensino possam receber estes alunos, a fim de seguir um caminho verdadeiro para inclusão.

Campos (2008) aponta as condições de inclusão de estudantes surdos no ensino regular, reforçando a necessidade da propagação da diversidade cultural surda, difundido a cultura surda, como seus costumes, modo de vida, seus enfrentamentos, dentre outros aspectos culturais para a inclusão de surdos no ensino regular e não somente a presença de intérprete ou treinamento do professor para aprender LIBRAS, corroborando assim com a criação da identidade do surdo como indivíduo.

Atualmente os recursos de tecnologia e mídia são bastante utilizados como ferramenta de auxílio para o professor. Esses recursos muitas vezes se destacam devido à comunicação visual que podem auxiliar no processo de construção de conhecimento. A língua de sinais brasileira também faz parte da visualidade, tendo em vista que é através de sinais com ou sem movimentos e expressóes faciais que existe a comunicação.

Para entender como a visualidade contribui para a junção de vários pensamentos, é necessário entender a diferença entre visualidade e visibilidade. A visualidade é quando a qualidade do signo visual ${ }^{2}$ provém da relação entre a imagem e a percepção do indivíduo, já a visibilidade não tem relação com a imagem, porém se produz a partir dela.

O processo de visualidade constitui opiniôes provenientes da imagem e de discursos viso espaciais, causando novas maneiras de ação sensorial. Campello (2008) relata que o que captamos sensorialmente pelos olhos é apenas uma pista que é enviada aos sistemas neuronais, posteriormente, esses dados, através de operações mais complexas informam nosso cérebro produzindo sentido no que estamos vendo.

Por essa razão os pensamentos são complexos e necessitam de interpretação, nesse contexto é necessário dar um novo significado à relação do estudante com o conhecimento no sentido de ensinar e aprender. $\mathrm{O}$ professor ao produzir um material visual atrelado à língua de sinais brasileira deve considerar as especificidades do signo visual e de como será processada essa informação pelo sujeito.

É importante também discutir o conceito de signo visual, destacando as necessidades específicas a visualidade. Para tanto precisamos entender a relação que o surdo tem com o mundo, pois não ouvir pode intensificar os demais sentidos. Com 
o processo de adaptação o surdo aprende a criar estratégias de interpretação dos indícios sonoros.

Campello (2008) destaca que os surdos de nascença que desconhecem totalmente a sonorização sentem a presença dos elementos que acompanham o som, com essa percepçáo aprendem a dar significados levando-os a interpretaçáo. A autora retrata algumas situações em que o surdo é capaz de ter essa percepção ao som. Como perceber quando algo vai cair e imaginar qual o tipo de barulho que vai causar, perceber a expressão de desagrado das pessoas em suas faces quando ouvem risco de giz em um quadro negro.

Tais interpretaçôes são caracterizadas como "sons imaginários" podendo substituir o "não ouvir". A visão também é condicionada a suprir a ausência da audição, a percepção visual da mesma forma que a percepção sensorial tende a ser construída e aprimorada com a prática.

A língua de sinais faz parte da representação visual. Vale ressaltar que é através da utilizaçáo da imagem e uso visual da língua de sinais que o surdo percebe a informação e lhe dá significado construindo assim o conhecimento. Se a língua de sinais não for utilizada de forma correta, a informação pode não ser bem compreendida pelo surdo e terá perda no sentido da informação. No universo visual, a presença de símbolos se faz constante. Tudo que é visto contribui para a construção de relaçóes e significados, formando representaçóes no seu mundo particular sem som, e por isto deve ser expressada a língua de sinais corretamente utilizando seus movimentos gestuais corretos para a compreensão correta da informaçáo.

Quanto aos materiais didáticos utilizados para estudantes surdos no ensino regular Hildebrand et al. (2011) apontam a necessidade de material específico para educar surdos e ouvintes, pois o livro didático usado é o mesmo de todo o ensino regular (contendo textos literários em português, exercícios, orientaçóes e imagens ilustrando os textos). Ou seja: é necessário o desenvolvimento de materiais didáticos que contemplem o ensino bilíngüe a fim de difundir a cultura surda e integrar melhor os estudantes ouvintes e surdos numa mesma atividade, a fim de se promover uma aprendizagem significativa.

Segundo a teoria cognitivista de Ausubel, considera-se como aprendizagem significativa o conhecimento que o estudante adquire através de conhecimento prévio obtido pelo professor para ter uma melhor abordagem do tema e melhor interesse do estudante. Para isto, é necessário que o professor verifique o que o estudante já conhece de determinado assunto e através do que o educando conhece relacionar com o conteúdo científico a trabalhar.

Moreira (2014) ressalta que os estudantes do ensino fundamental já têm o conhecimento subsunçor estabelecido devido ao trabalho dos professores nos anos anteriores, além da experiência vivida no meio familiar pelo educando e que este conhecimento assimilado serve também de subsunçor para o conteúdo a se trabalhar.

Neste sentido, indiferente das dificuldades apresentadas em uma sala de aula do ensino regular é necessário que o professor saiba o que seus estudantes ouvintes 
e surdos possuem de conhecimento prévio sobre determinado assunto, para isto é necessária a comunicaçáo entre este professor e o estudante surdo através da língua de sinais ou mediação de um intérprete.

O professor deve ter o olhar voltado para a realidade social e educacional do estudante para que isto facilite a maneira de abordar o conteúdo, além de facilitar a relação professor/estudante conquistando a empatia do educando. Se o educador não enxergar o estudante como sujeito no processo ensino/aprendizagem resultará em aulas superficiais, que não atinjam o estudante de modo a superar suas dificuldades, pois este será influenciado pela maneira de trabalhar do profissional, tendo em consideração suas falas, atitudes e posiçóes.

Partindo desses pressupostos, a atividade lúdica pode ser uma eficaz ferramenta para auxilio no processo de ensino e aprendizagem. Todavia se faz necessário que o professor utilize de metodologias dinâmicas e provocadoras, visando instigar a curiosidade dos estudantes proporcionando assim, prazer e interaçáo na aprendizagem, surtindo efeito positivo, pois, o estudante deixa de ser expectador e passa a ser sujeito da aula, contribuindo para o desenvolvimento cognitivo.

Nessa perspectiva os jogos didáticos podem ser considerados como fatores importantes na educação. O jogo é uma brincadeira, onde o estudante tem a oportunidade de experimentar, descobrir, inventar, aprender e aprimorar suas habilidades, estimulando sua autonomia e autoconfiança. Desenvolvendo ao final do processo a melhora cognitiva, agregando conhecimento, potencializando sua atençáo e concentração, além, de promover socialização e cooperação entre os participantes.

Quando o jogo didático é trabalhado em grupo, pode estimular questóes emocionais, morais e sociais que são essenciais no processo de formação do indivíduo como cidadáo. Rebelo (2015) destaca que ao se relacionar em equipe, é possível promover aos estudantes o estímulo ao raciocínio lógico de forma divertida e dinâmica, pois, nessa interaçáo todos participam das atividades.

De acordo com a teoria de Piaget, os jogos possuem uma classificação, podendo ser divididos de acordo com a faixa etária que o estudante se encontra, seguindo a categoria correspondente ao estágio mental da criança (Marrega, 2014). Nessa premissa destacam-se os jogos de regras, pois estes são indicados segundo a classificação de Piaget para idades entre sete a doze anos, sendo em média está a faixa etária que é proposto no presente trabalho.

Este tipo de jogo contribui para a socialização e a cooperação entre os membros participantes, pois, costumam ser mais coletivos. O estudante entende que, se as regras são violadas a equipe toda é prejudicada, despertando assim, o sentimento de uniâo e também de competição.

Diferente do material pedagógico, o jogo didático possui características lúdicas possibilitando uma melhora do desempenho dos estudantes em determinados conteúdos de difícil aprendizagem. Todavia, o jogo é o eixo que conduz a um conteúdo didático específico, resultando em um empréstimo da ação lúdica para a aquisi- 
ção de informações (Kishimoto, 1996). Em seu livro "O jogo e a Educação Infantil" (1994), Kishimoto descreve três diferentes visóes referentes ao jogo: (1) pode ser o resultado de um sistema linguístico que funciona dentro de um contexto social; (2) pode ser considerado um sistema de regras; (3) pode ser visto como um objeto.

A primeira visão relacionada ao jogo é ocasionada de acordo com a linguagem de cada contexto social. Nesse contexto as línguas são fontes de expressão é através delas que se denominam quadros socioculturais. Sendo assim, o jogo atribui à imagem, o sentido que diferentes sociedades lhes apresentam, isso explica porque o jogo tem tantas distinçóes, com diferentes estruturas, de acordo com sua época e/ou lugar.

A segunda visão do jogo trata de um conjunto de regras possibilitando observar a estrutura sequencial, a qual define em qual modalidade o jogo se encaixa. É através das regras que se aplica o lúdico, considerando que, o jogador estará executando as regras do jogo e juntamente estará agregando informaçóes.

A terceira e última visão refere-se ao jogo como objeto, nesse sentido a autora usa como exemplo o jogo de xadrez, onde, é possível materializá-lo no tabuleiro e nas peças, podendo fabricá-las com papelão, madeira, plástico, pedra ou metais. Permitindo assim, que a criança explore o jogo e conheça os diferentes significados de acordo com cada cultura, regras e objetos caracterizados.

O jogo torna-se a diversão que contribui para lapidar a busca exploratória. A incerteza, a diversão e a espontaneidade favorecem o processo investigativo necessário para a resoluçáo do problema apresentado, tornando o estudante menos egocêntrico e mais flexível.

\section{Material e métodos}

Foi realizada uma atividade lúdica abordando o tema Biomas Brasileiros, na disciplina de ciências para o $6^{\circ}$ ano do ensino fundamental em uma escola de ensino regular da rede estadual de educação da cidade de Ponta Grossa - PR, a qual foi escolhida por levantamento junto ao Núcleo Regional de Educação do Estado do Paraná, buscando-se uma instituição que contemplasse a presença de estudantes surdos e ouvintes em uma mesma classe do ensino regular (classe mista).

Foram realizadas quatro visitas na escola, sendo a primeira para dialogar com a direção, professor de ciências e intérprete, buscando também conhecer o estudante surdo (aspectos inerentes à sua cultura e identidade) e obter as autorizaçóes necessárias para realização do trabalho (termos de consentimento livre e esclarecido dos responsáveis pelos estudantes da classe).

Obteve-se junto à direção a informação de que o estudante surdo teve encefalocele ao nascimento. Segundo Barreto et al. (1993), a encefalocele é uma protrusão do conteúdo do crânio além dos seus limites normais, através de uma má-formação óssea congênita associada ou, mais raramente, através de forames ou fissuras normais ao crânio. Pode estar relacionada a agentes teratogênicos. Em testes de laboratório, agentes virais, radiação, salicilatos, hipertermia, hipoxia e outros agentes produziram estas más-formaçôes, porém seus mecanismos exatos são ainda discutidos. Porém, 
esta condição não interfere no aprendizado do portador, que recebeu tratamento médico adequado por toda sua vida.

Após se obter todas as informaçôes e autorizações necessárias, foi realizado um encontro com a professora de ciências e a intérprete, a fim de mostrar a atividade proposta e se obter sugestôes para adapta-la de acordo com a realidade dos estudantes. O próximo encontro foi diretamente com a classe, onde foi ministrada uma aula sobre o conteúdo (Biomas), destacando as características da fauna e as diferenças de clima e regiâa de cada formação (Figura 1). Com o auxílio da intérprete foram abordados sinais em libras de cada animal. $\mathrm{O}$ último encontro foi para aplicação da atividade lúdica.

A atividade foi realizada utilizando-se um mapa do Brasil contendo divisóes dos biomas (Figura 2), com legendas de identificação em língua portuguesa e alfabeto em libras. Este material foi produzido em Coreldraw, impresso em papel adesivo e colado em um painel magnético. Também foram utilizadas cartas de perguntas e respostas, com os respectivos animais de cada bioma, contendo o nome do animal na língua portuguesa e a legenda com o alfabeto em libras na carta resposta. Na carta pergunta colocaram-se as descriçôes dos animais (coloração, hábitos e habitats), constando em cada uma o sinal do animal em libras. Foram confeccionadas 30 cartas no total, impressas em imãs personalizados para que pudessem se aderir ao quadro magnético.

Para realização da atividade a turma foi dividida em duas equipes (com 12 e 13 estudantes respectivamente) para as quais distribuiu-se as cartas de perguntas e respostas. As equipes iniciaram o jogo fazendo perguntas uma para as outras, utilizando-se da carta de respostas. A leitura das cartas pelos próprios estudantes foi feita voltando-se para o aluno surdo e falando pausadamente, sendo utilizado o sinal em libras do animal correspondente. Ao acertar a resposta a equipe também deveria anexar a carta corretamente no mapa. A prática ocorreu alternando as equipes de modo que todos participassem fazendo perguntas e respondendo, somando pontos para equipe. Antes do início do jogo, foram estabelecidas regras de conduta com punição em forma de pontos, para que a atividade pudesse transcorrer sem perturbaçóes. Todas as etapas foram acompanhadas pela intérprete. 
Figura 1 - Aula sobre Biomas ministrada na classe mista do $6^{\circ}$ ano

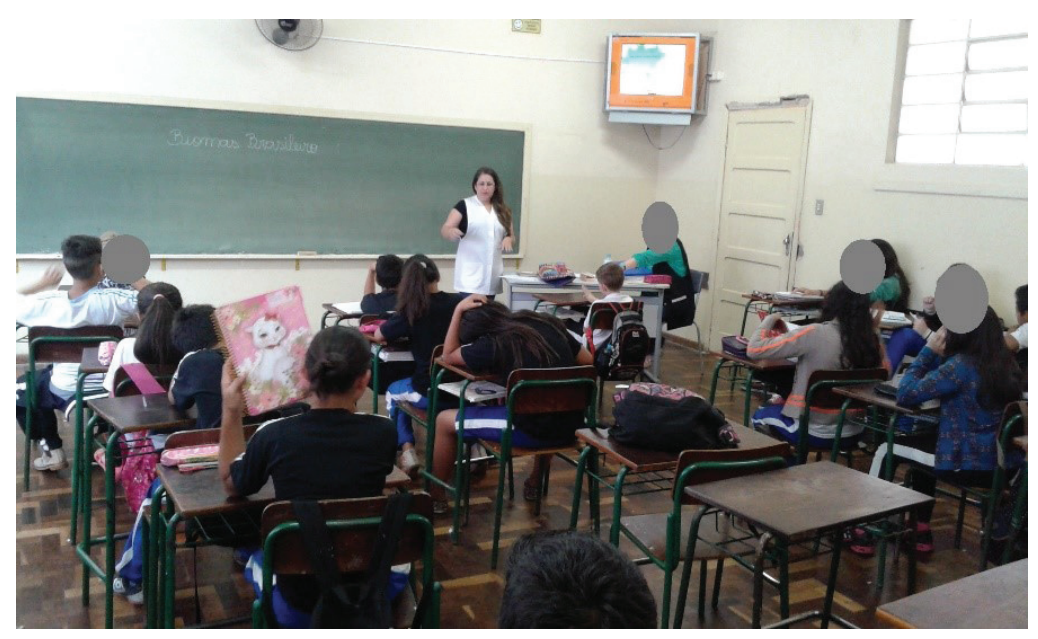

Figura 2: Mapa de Biomas e cartas utilizadas para a atividade lúdica

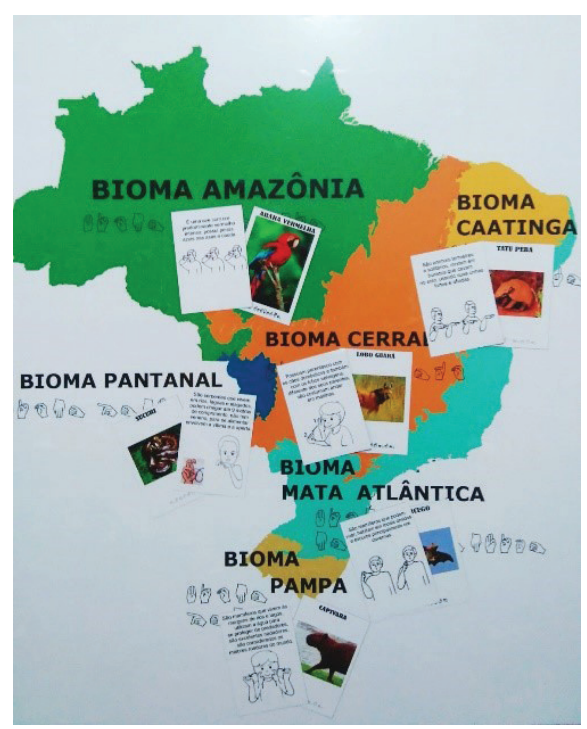

Fonte: ESPINDOLA e CARNEIRO (2016). 


\section{Resultados e discussão}

Os resultados foram analisados de forma qualitativa dividindo-se em três etapas: (1) quantidade de acertos; (2) interação e (3) participação dos estudantes (análise feita pelos pesquisadores e por meio de um questionário aplicado para a intérprete e a professora da disciplina que estavam presentes durante todo o processo).

Quanto à quantidade de acertos ficou perceptível que os estudantes sabiam sobre os animais, características físicas, coloração, hábitos, porém a maioria teve dificuldade em localizar o bioma que os animais pertenciam. Segundo Silva (2012) o tema ecologia é trabalhado nas escolas ao longo do ensino básico, sendo distribuído principalmente nos $6^{\circ}$ e $7^{\circ}$ anos do ensino fundamental, na disciplina de Ciências, além de ser visto como tema transversal (Meio Ambiente), na proposta do Ministério da Educação e Cultura (MEC) que consta nos Parâmetros Curriculares Nacionais (BRASIL, 1999). Porém, sabe-se das dificuldades de ensino e aprendizagem enfrentadas no ensino público brasileiro, principalmente a dificuldade de se ajustar a teoria com a realidade, que segundo Arruda e Laburu (1998) é uma necessidade, para que ocorra uma organização de fatos e experimentos, considerando a realidade do aluno. Embora os alunos tenham sido capazes de identificar conceitos de forma separada, ao se buscar ligaçóes entre os animais e os biomas, notou-se a fragmentaçáo de conhecimentos.

Quanto à interação entre a classe, notou-se que os estudantes já tinham certo conhecimento de libras e que o aluno surdo conseguiu compreender a atividade, participando e acertando a resposta do jogo com base no sinal feito por um colega. Esta situação observada reforça a importância do bilinguismo para a construção do conhecimento de alunos surdos no contexto de educação inclusiva, bem como o aumento da interação entre a classe.

Uma das dificuldades que os estudantes relataram foi referente à ansiedade que sentiram em responder rápido devido ao tipo da atividade, que trouxe à tona o espírito competitivo e a euforia em marcar pontos. Embora possa ter sido um fator limitante nesse aspecto (pois algumas vezes os estudantes esqueciam-se de se comunicar voltados para o colega surdo), por outro lado incitou a participação efetiva de toda a turma. Porém, o estudante surdo não se excedeu em momento algum, parecendo estar concentrado em compreender os sinais feitos pelos colegas mesmo tendo o auxílio da intérprete.

Através da atividade aplicada percebeu-se a dificuldade que o professor tem em controlar a euforia dos estudantes ouvintes aliada a atenção necessária que o estudante surdo precisa. Cabe então refletir sobre o papel da formaçáo inicial e continuada dos docentes para a educação inclusiva. Segundo Quadros (2003, p.86), a educação para alunos surdos é multifacetada, mas apresenta características que são específicas, pois ela é visual, e traduz-se de forma visual.

Para Dorziart et al (2007), é importante desenvolver práticas curriculares que atendam a demanda e necessidades de todos os alunos ingressantes no sistema educacional, pois sem uma atenção especial a isso, institui-se um mecanismo de exclusão 
subliminar perversa, que ocorre por dentro do sistema sem ser vista. $\mathrm{Na}$ atividade proposta buscou-se dar a todos a mesma oportunidade, visando uma prática que atendesse à situação da turma toda.

No questionário respondido pela professora de ciências e pela intérprete, ambas declararam que nunca tinham realizado atividade similar à esta, afirmando que a atividade aplicada contribuiu para interação dos estudantes e inclusão do aluno surdo à classe, porém a intérprete ressaltou a importância de uma possível participaçấo mais efetiva do segundo. Acredita-se que isso possa ter sido apontado devido ao fato de que o estudante surdo demonstrava maior concentração e observação da turma, enquanto os colegas estavam mais eufóricos com a atividade, por vezes até gritando. Porém, não pode ser considerado necessariamente como falta de interação.

Segundo Lorenzini (2004) é importante reforçar que a adoção do bilinguismo em sala de aula é fundamental, bem como investimento em pesquisas sobre a língua de sinais, a fim de reconhecer e valorizar cada vez mais as formas de expressão e comunicação de surdos. A comunicação total muito contribuiu para este momento da educaçáo de surdos, pois foi por meio dessa filosofia que se começou a admitir a língua de sinais como meio de aprendizado e comunicação do sujeito surdo.

Com relação à compreensão dos conceitos propostos, ambas entrevistadas declararam que o jogo foi um facilitador de aprendizagem, pois as imagens tornaram a atividade divertida e dinâmica.

Segundo Oliveira e Benite (2015), ainda há um grande caminho a percorrer, pois o bilinguismo na prática ainda não acontece nas escolas e muitas vezes a LIBRAS adquire um aspecto secundário na sala de aula. Além do que, o intérprete não é professor do aluno surdo e não deve assumir a função de ensinar ciências. Para tanto, é preciso que os professores tenham a mínima noçấo de LIBRAS, a fim de estabelecer contato com o aluno surto e compreender suas dúvidas. Isso não pressupóe que o professor deva ser intérprete ou que o intérprete deva ser substituído, pelo contrário: segundo os autores, o trabalho simultâneo por um profissional é inviável, pois o professor é responsável pelo ensino/aprendizado, enquanto o intérprete se dedica à intepretação/tradução.

\section{Considerações finais}

Foi perceptível o envolvimento dos estudantes na atividade, sendo confirmado que a atividade lúdica é um instrumento que colabora para o processo ensino/ aprendizagem, promovendo interação entre os estudantes. Mas a maior dificuldade no ensino de ciências para surdos ainda é a barreira linguística, pois o pouco domínio da língua de sinais pelos ouvintes faz com que se dificulte a interação e o aprendizado pelo surdo.

É importante expandir a compreensão de que os sinais e movimentos são fundamentais para que ocorra a comunicação na língua de sinais. Portanto, quando não são feitos corretamente pelos ouvintes, a informação não é percebida corretamente ou completamente pelo surdo. Neste sentido, aprimorar o uso de estratégias didáticas 
que contemplem o aspecto visual, aliadas à contextualização do conteúdo são essenciais para melhorar o processo como um todo.

É preciso constante reflexão dos docentes sobre práticas inclusivas a fim de permitir o acesso ao conteúdo científico de forma igualitária, não havendo exclusão devido as necessidades especiais. Considera-se necessário que o professor utilize atividades lúdicas facilitando o processo de inclusão e de aprendizado em classes mistas.

\section{Referências}

ARRUDA, S.M.; LABURU, C.E. Considerações sobre a função de experimento noensino de Ciências. In: NARDI, Roberto (Org.). Consideraçóes atuais no ensino de Ciências. São Paulo: Editora Escrituras, 1998. p. 73-87.

BARRETO,E.O.; BARBOSA, J.E; TELLES, C.S. Classificação Anatômica das Encefaloceles anteriores. Arquivos de Neuropsiquiatria. 61(1):107-111. 1993.

BRASIL. Decreto n ${ }^{\text {5.626, de }} 22$ de dezembro de 2005. Regulamenta a Lei no 10.436, de 24 de abril de 2002, que dispóe sobre a Língua Brasileira de Sinais - Libras, e o art. 18 da Lei no 10.098, de 19 de dezembro de 2000. Diário Oficial [da] República Federativa do Brasil, Brasília, DF, 23 de dezembro de 2005. Disponível em: <http://www.planalto.gov.br/ccivil_03/_ato2004-2006/2005/decreto/d5626.htm>. Acesso em: 06 maio 2016.

BRASIL. Política Nacional de Educaçáo Especial na Perspectiva de Educaçáo Inclusiva. Jan, 2008. p. 14. Disponível em: <http://portal.mec.gov.br/arquivos/pdf/politicaeducespecial.pdf>. Acesso em: 09 maio 2017.

CAMPELLO. S. R. A. Aspectos da visualidade na educação de surdos. Tese (Doutorado em Educação) Universidade Federal de Santa Catarina. Florianópolis. 2008, 245 f. Disponível em: <https://repositorio.ufsc. br/xmlui/handle/123456789/91182>. Acesso em: 08 maio 2016.

CAMPOS, M. L. I. L. Cultura surda: possível sobrevivência no campo da inclusăo na escola regular? Dissertação. (Mestrado em Educação) - Universidade Federal de Santa Catarina. Florianópolis. 2008, 222 f. Disponível em: <https://repositorio.ufsc.br/bitstream/handle/123456789/91426/259181.pdf?sequence=1>. Acesso em: 05 de Maio de 2016.

DOZIART, A.; LIMA, N. M. F.; ARAÚJO, J. R. A inclusão de surdos na perspectiva dos estudos culturais. Informativo Técnico Científico Espaço, INES. Rio de Janeiro, n 28, p.16-27, jul/dez. 2007.

ERDMANN, R. H.; REBELO, L. M. B. Aprendizagem e Subjetividade no processo de formação estratégica. In: $1^{\circ}$ Encontro de estudos em estratégia. Curitiba, 2003.

HILDEBRAND, H. R. et al. Desenvolvimento de Material Didático para Surdos: As Relaçôes entre Imagens e Escritas. XI Congresso Luso Afro Brasileiro de Ciências Sociais (XI CONLAB), UFBA, Salvador, 2011. Disponível em: <http://docplayer.com.br/4991497 - Desenvolvimento-de-material-didatico-para-surdos-as-relacoes-entre-imagem-e-escrita.html>. Acesso em: 06 maio 2016.

KISHIMOTO. M. T. O jogo e a educaçáo infantil. São Paulo. Editora Pioneira. 1994. Disponível em: <file://C:/Users/windows/Downloads/10745-32465-1-PB.pdf>. Acesso em: 06 Jul 2016.

KISHIMOTO. M. T. Jogo, brinquedo, brincadeira e a educaçáo. Cortez, São Paulo, 1996. Disponível em: $<$ https://favenieducacaol.files.wordpress.com/2012/10/kishimoto-o-jogo-e-a-educac3a7c3a3o-infantil.pdf>. Acesso em: 06 jul. 2016.

LORENZINI, N. M. P. Aquisiçáo de um conceito científico por alunos surdos de classes regulares do ensino fundamental. 2004. 156 f. Dissertação (Mestrado emEducação) - Universidade Federal de Santa Catarina, Florianópolis, 2004

MACHADO, P. C. Integraçáo/Inclusáo na escola regular: um olhar do egresso surdo. In: QUADROS,

R. M. (Org.) Estudos Surdos I. Petrópolis, RJ: Ed. Arara Azul, 2006, p. 38-75.

MARREGA, S. N. Jean Piaget e as fases do desenvolvimento infantil. Artigo publicado no Site Portal Educação. Disponível em: <http://www.portaleducacao.com.br/psicologia/artigos/55035/jean-piaget-e-as-fases-dodesenvolvimento-infantil>. Acesso em: 25 maio 2016.

MOREIRA, M. A. Teorias da Aprendizagem. 2 ed. [reimpr.]. São Paulo. E.P.U. - Editora Pedagógica e Universitária. 2014. 
OLIVEIRA, W.D.de; BENITE, A.M.C. Aulas de ciências para surdos: estudos sobre a produção do discurso de intérpretesde LIBRAS e professores de ciências. Ciência e Educaçáa, Bauru, v. 21, n. 2, p. 457-472, 2015

PIAGET, J. O Nascimento da inteligência na criança. Coleçâo Plural n 10. 9 ed. Portugal: Dom Quixote, Out, 1986.

QUADROS, R. M. Situando as diferenças implicadas na educação de surdos: inclusão/exclusão. Ponto de Vista. Florianópolis, n.05, p. 81-111, 2003.

RODRIGUES, C. H. e QUADROS de, R. M. Diferenças e linguagens: a visibilidade dos ganhos surdos na atualidade. Revista Teias, v. 16, n. 40, p. 72-88, 2015. Disponível em: <http://www.periodicos.proped.pro.br/ index.php/revistateias/article/view/1709/1360>. Acesso em: 06 maio 2016.

ROSSI. R. A. Pressupostos e Implicações das Políticas Educacionais da Educação Inclusiva do Século XX E XXI: em foco a educação dos surdos brasileiros. V Seminário Nacional de Educaçáo Especial. 2012. Disponível em: <http://www.cepae.faced.ufu.br/sites/cepae.faced.ufu.br/VSeminario/trabalhos/299_1_1.pdf>. Acesso em: 14 maio 2017

SILVA, M de C. Ensino de ecologia: dificuldades encontradas e uma proposta de trabalho para professores dos ensinos fundamental e médio de João Pessoa, PB. Monografia. Universidade Federal da Paraíba, 2012.

\section{Notas}

${ }^{1}$ Classe mista: turma de alunos composta por alunos ouvintes e um ou mais alunos surdos.

${ }^{2}$ Signo visual.

\section{Correspondência}

Lia Maris Orth Ritter Antiqueira - Universidade Tecnológica Federal do Paraná, Campus Ponta Grossa. Avenida Monteiro Lobato - KM 04, Jardim Carvalho. CEP: 84016210. Ponta Grossa, Paraná, Brasil.

E-mail: danielspindola@yahoo.com.br - danitelles@live.com - taliciagalan@utfpr.edu.br - liaantiqueira@utfpr. edu.br

Recebido em 20 de novembro de 2016

Aprovado em 22 de maio de 2017 
